\title{
Porphyromonas gingivalis activates NFKB and MAPK pathways in human oral epithelial cells
}

\author{
Sabine Groeger ${ }^{1 *}$, Fabian Jarzina ${ }^{1}$, Eugen Domann ${ }^{2}$ and Joerg Meyle ${ }^{1}$
}

\begin{abstract}
Background: The bacterial biofilm at the gingival margin induces a host immune reaction. In this local inflammation epithelial cells defend the host against bacterial challenge. Porphyromonas gingivalis (P. gingivalis), a keystone pathogen, infects epithelial cells. The aim of this study was to investigate the activation of signaling cascades in primary epithelial cells and oral cancer cell lines by a profiler PCR array.

Results: After infection with P. gingivalis membranes the RNA of 16 to 33 of 84 key genes involved in the antibacterial immune response was up-regulated, amongst them were IKBKB (NF-KB signaling pathway), IRF5 (TLR signaling) and JUN, MAP2K4, MAPK14 and MAPK8 (MAPK pathway) in SCC-25 cells and IKBKB, IRF5, JUN, MAP2K4, MAPK14 and MAPK8 in PHGK. Statistically significant up-regulation of IKBKB $(4.7 \times)$, MAP2K4 $(4.6 \times)$, MAPK14 $(4.2 \times)$ and IRF5 $(9.8 \times)(p<0.01)$ was demonstrated in SCC-25 cells and IKBKB $(3.1 \times)$, MAP2K4 $(4.0 \times)$ MAPK $14(3.0 \times)(p<0.05)$, IRF5 $(3.0 \times)$ and JUN $(7$. $7 \times)(p<0.01)$ were up-regulated in PHGK.
\end{abstract}

Conclusions: $P$. gingivalis membrane up-regulates the expression of genes involved in downstream TLR, NFKB and MAPK signaling pathways involved in the pro-inflammatory immune response in primary and malignant oral epithelial cells.

Key words: Signaling pathway, MAPK, NF-KB, Oral cells, P. gingivalis

\section{Background}

Porphyromonas gingivalis ( $P$. gingivalis), an anaerobic Gram-negative rod, is a member of the oral bacterial biofilm and considered as an important etiologic agent of gingival and periodontal inflammation [1]. P. gingivalis is able to invade oral epithelial and endothelial cells [2-4] and effectively induces pro-inflammatory cytokine production of monocytes, neutrophils, as well as macrophages. It is also able to modify the functions of immune cells in vitro and in vivo $[5,6]$.

Epithelial cells not only provide a barrier against bacterial challenge and invasion but also participate in the innate immune defense. Infection of epithelial cells by $P$. gingivalis activates signaling cascades that control transcription of target genes encoding for immune response and inflammatory reactions such as interleukin (IL)- $1 \beta$, IL-6, IL-8 and tumor necrosis factor (TNF)- $\alpha$ in

\footnotetext{
* Correspondence: Sabine.E.Groeger@dentist.med.uni-giessen.de ${ }^{1}$ Department of Periodontology, Justus-Liebig-University of Giessen, Giessen, Germany

Full list of author information is available at the end of the article
}

monocytic and epithelial cells and interferon regulating factor (IRF) 6 in oral epithelial cells [7-9].

Pattern recognition receptors (PRRs) recognize microbial components formed as pathogen-associated molecular patterns (PAMPs). PAMPs show structural similarities between a great numbers of microorganisms, thus different PRRs usually recognize well-defined PAMPs. Toll-like receptors (TLRs) form a well-known PRR family [10]. PRRs are present on epithelial cells, neutrophils, macrophages and dendritic cells (DCs) [11]. Activation of these receptors by PAMPs initiates the innate response to $\mathrm{mi}$ crobial challenge and induces adaptive immunity to clear infections [12, 13].

Recent studies suggest that PRRs are responsible for constant surveillance of the microbial colonization by detecting conserved microbial structures such as lipopolysaccharides (LPS) [14, 15].

Intracellular invasion of pathogens is recognized by nucleotide-binding oligomerization domain (NOD)-like receptors (NLRs) which are located in the cytoplasm. Purinergic P2X receptors on the plasma membrane are 
activated by damaged cells $[16,17]$. Ligation of the purinergic receptor, $\mathrm{P} 2 \mathrm{X} 7$, induces the assembly of the inflammasome, a protein complex of caspase- 1 and an adaptor protein ASC. Activation of caspase-1 initiates the production and release of the pro-inflammatory cytokines IL-1 $\beta$ and IL-18. The adaptor protein, apoptosisassociated speck-like protein NLRP3 is the best studied NLR member. It contains a CARD (ASC) domain and the protease caspase-1 $[18,19]$.

Gingival epithelial cells (GECs) may exhibit a functional NALP3 inflammasome. Stimulation of GECs with LPS or infection with $P$. gingivalis caused induction of the IL- $1 \beta$ gene and accumulation of IL- $1 \beta$ in the cells. However, IL-1 $\beta$ release did not occur unless the LPStreated or infected cells were stimulated with adenosine triphosphate (ATP). GECs showed caspase-1 activation after treatment with ATP [20]. P. gingivalis expresses a nucleoside-diphosphate kinase (NDK) homolog that is able to inhibit innate immune reaction caused by stimulation with extracellular ATP. Thus, $P$. gingivalis infection inhibits ATP-induced caspase-1 activation in GECs. Furthermore $P$. gingivalis NDK may modify high- mobility group protein B1 (HMGB1) release. HMGB1 is a pro-inflammatory danger signal that, in intact cells remains associated with chromatin. HMGB1 is released into the extracellular area after stimulation of uninfected GECs with ATP instead of being translocated from the nucleus into the cytosol. In comparison to wild-type $P$. gingivalis higher amounts of HMGB1 are released when cells are infected with a NDK-deficient mutant stimulated with ATP, suggesting that NDK is crucial in inhibiting the initiation of the P2X7-dependent inflammasome and HMGB1 release from infected GECs [21].

GECs belong to the first host cells which encounter with colonizing oral bacteria. The bacterial-host communication is managed by signal transduction pathways, i.e. the mitogen-activated protein kinase (MAPK) and TLR pathway that are activated by infection with Fusobacterium nucleatum (F. nucleatum) and Streptococcus gordonii and other bacteria of the oral biofilm [22-24].

Molecules supporting antimicrobial clearance and the control of adaptive and innate immune responses are human beta-defensins (hBDs) produced by various cell types. Investigation of the macrophage cell line RAW 264.7 revealed that treatment with synthetic hBD3-3 peptide inhibited the LPS-induced production of inducible nitric oxide synthase and nitric oxide. Furthermore this treatment inhibited the production of secretory cytokines, such as IL- 6 and tumor necrosis factor (TNF)- $\alpha$ in cells stimulated with LPS. This inhibition was found to be concentration-dependent. Additionally, in a model of lung inflammation, hBD3-3 was shown to reduce interstitial infiltration by neutrophils. HBD3-3 was able to downregulate the nuclear factor-kappa B (NF-kB)- dependent inflammatory response via direct suppression of the phosphorylated-nuclear factor of kappa light polypeptide gene enhancer in B-cells inhibitor alpha ( $\mathrm{I} \mathrm{KB} \alpha)$ degradation and downregulation of the p65 unit of activated NF-kB [25].

$P$. gingivalis is capable of inducing immune tolerance in antigen-presenting cells (APCs) by desensitizing them against second activation, a process that involves induction of the expression of the tolerogenic molecules immunoglobulin-like transcript 3 (ILT-3) and B7-H1 [26]. It is known that $\mathrm{T}$ cell activation requires a costimulatory signal usually provided by APCs. This additional signal regulates activation or inhibition of $\mathrm{T}$ cell action.

In a previous study, we demonstrated that $P$. gingivalis induces $\mathrm{B} 7-\mathrm{H} 1$ expression in different carcinoma cell lines (SCC-25 cells, BHY cells) as well as in primary human gingival keratinocytes [27]. The B7-H1 receptor (synonymous PD-L1) belongs to the B7-family exhibiting regulatory properties that modify cell-mediated immune reactions $[28,29]$. B7-H1 ligands are induced on activated $\mathrm{T}$ and $\mathrm{B}$ cells, on endothelial and epithelial cells as well as on macrophages. Dendritic cells (DCs) and APCs exhibit constitutive B7-H1expression [30-32]. The binding receptor for $\mathrm{B} 7-\mathrm{H} 1$ is the CD28/CTLA-4 like programmed death-1 (PD-1) receptor which is expressed on activated $\mathrm{T}$ cells, $\mathrm{B}$ cells, monocytes and macrophages. This molecule is a member of the immunoglobulin (IG) superfamily [33]. Signals mediated by B7-H1 are essential in regulating $\mathrm{T}$ cell activation and tolerance [34], by inhibiting functions of activated $\mathrm{T}$ cells. Proinflammatory cytokines i.e. interferon (IFN)- $\gamma$ are known to up-regulate $\mathrm{B} 7-\mathrm{H} 1$ expression $[35,36]$. Activated $\mathrm{T}$ cells, B cells and monocytes show PD-1 expression [37].

B7-H1 ligand binding triggers the development of regulatory $T$ cells $\left(\mathrm{T}_{\text {reg }}\right)$. This phenotype is essential in regulating peripheral tolerance by active suppression of effector $\mathrm{T}$ cells and inhibition of tissue damage caused by the inflammatory response [38-40]. Blockade of B7$\mathrm{H} 1$ affected the inhibitory effect of $\mathrm{T}_{\text {reg }}$ [41]. Additionally, blockade of B7-H1/PD-1 ligation abolished $\mathrm{T}_{\text {reg }}$ mediated immune-regulation [42]. This was demonstrated in a mouse model expressing a phenotype with B7-H1 deficiency that caused diminished $\mathrm{T}_{\text {reg }}$ cell differentiation in vivo [43]. The underlying mechanisms are not completely understood. Using bladder cancer cells, B7-H1 up-regulation was shown to be induced by TLR4 signaling [44], and in oral Langerhans cells activation of TLR4 caused induction of B7-H1 in vitro $[45,46]$.

The aim of this study was to investigate the regulation of a selected number of genes after infection with $P$. gingivalis. The study was conducted to analyze mechanisms that are induced in epithelial cells after bacterial challenge. The analysis was performed on genes coding for 
receptor activation, downstream signal transduction, apoptosis, inflammatory response, cytokines and chemokines, and antimicrobial peptides.

\section{Materials and methods}

\section{Bacteria and growth conditions}

P. gingivalis strain W83 was purchased from the American Type Culture Collection (ATCC BAA- $308^{\text {mit }}$, LGC Standards $\mathrm{GmbH}$, Wesel, Germany) and grown at $37{ }^{\circ} \mathrm{C}$ in brain-heart-infusion broth (Difco, BD, Heidelberg, Germany) with hemine $(5 \mu \mathrm{g} / \mathrm{ml})$ and menadione $(1 \mu \mathrm{g} / \mathrm{ml})$ (Sigma-Aldrich, Munich, Germany) under anaerobic conditions using the Anaerocult A System (Merck, Darmstadt, Germany).

\section{Cell cultures}

The human squamous cell carcinoma cell line SCC-25 was purchased from the DSMZ (German Collection of Microorganisms and Cell Cultures, Braunschweig, Germany, DSMZ number ACC 617) and cultured in a medium containing Dulbecco's minimal essential medium (DMEM):Ham's F12 (1:1, vol:vol), (Invitrogen, Karlsruhe, Germany) and $20 \%$ fetal calf serum (FCS, Greiner, Frickenhausen, Germany). Primary human gingival keratinocytes (PHGK) were obtained from gingival biopsies of healthy volunteers, prepared and cultured in a serumfree medium containing DMEM:Ham's F12 (4:1, vol:vol), 10 mM HEPES (Invitrogen, Karlsruhe, Germany).

\section{Bacterial cell fractionation}

The bacteria were harvested in the late exponential growth phase $\left(\mathrm{OD}_{600}\right.$ of 1.0) by centrifugation for $20 \mathrm{~min}$ at $6,500 \times g$ and $25{ }^{\circ} \mathrm{C}$. The bacterial pellet was resuspended in $50 \mathrm{ml}$ of $10 \mathrm{mM}$ HEPES, pH 7.4, containing protease inhibitor cocktail (4 mini-tablets of Complete, EDTA-free, Roche) and DNase I/RNase A $(20 \mu \mathrm{g} / \mathrm{ml}$ each). Bacteria were disrupted by four passages through a high-pressure cell disruption system (Model TS, $0.75 \mathrm{KW}$, Constant Systems Ltd.) at 40,000 psi. The cellular debris was removed by centrifugation at $8,000 \times g$ for $30 \mathrm{~min}$ at $4{ }^{\circ} \mathrm{C}$, and the membranes were sedimented from the cleared lysate at $150,000 \times g$ for $2 \mathrm{~h}$ at $4{ }^{\circ} \mathrm{C}$. The supernatant (cytosolic fraction) was stored, and the total membrane fraction was washed three times with $10 \mathrm{mM}$ HEPES, pH 7.4. The membrane pellet was subsequently re-suspended in $10 \mathrm{mM}$ HEPES, $\mathrm{pH}$ 7.4. The protein concentrations of all samples, i.e. cleared lysate, cytosolic fraction and total membranes, were determined using Bio-Rad's protein assay reagent. The purity of the fractions was confirmed by sodium dodecyl sulfate polyacrylamide gel electrophoresis (SDS PAGE) using a $10 \%$ gel following staining with coomassie brilliant blue (SERVA Electrophoresis GmbH, Heidelberg, Germany).
Infection of SCC-25 cells and membrane-stimulation of SCC- 25 cells and PHGK

For infection of SCC-25 cells and primary human gingival keratinocytes (PHGK), the cells were seeded in 6well plates $\left(1 \times 10^{6}\right.$ cells/well $)$ in antibiotic-free medium containing $1.8 \mathrm{mM}$ calcium chloride and 10\% FCS (Thermo Fisher Scientific, Darmstadt, Germany) and grown at $37{ }^{\circ} \mathrm{C}$ in a humidified atmosphere with $5 \% \mathrm{CO} 2$ to $80 \%$ confluency before stimulation.

Cells were infected with whole bacterial cells as well as treated with bacterial fractions. To prepare $P$. gingivalis W83 for infection, the bacterial cells were harvested in the late exponential growth phase $\left(\mathrm{OD}_{600}\right.$ of 1.0$)$ by centrifugation at $25{ }^{\circ} \mathrm{C}$ for $20 \mathrm{~min}$ at $6,500 \times g$. The supernatant was discarded, and the cell pellet was resuspended in DMEM:Ham's with 10\% FCS, adjusting the bacterial cell number on the basis of spectrophotometric measurements of the optical density of the bacterial suspension at $600 \mathrm{~nm}\left(\mathrm{OD}_{1}=10^{9}\right.$ cells $\left./ \mathrm{ml}\right)$. Infection of the SCC-25 cells was performed at a multiplicity of infection (MOI) of 100 for $24 \mathrm{~h}$. The bacterial membrane fractions from $P$. gingivalis W83 was used in a concentration of $50 \mu \mathrm{g} / \mathrm{ml}$. A non-treated control containing cells only in culture medium was carried in every experiment. SCC-25 cells and PHGK were treated with the bacterial fractions for $24 \mathrm{~h}$ at $37{ }^{\circ} \mathrm{C}, 95 \%$ air, $5 \% \mathrm{CO}_{2}$ and $92 \%$ relative humidity and harvested by scraping in RNA protect solution (Qiagen) for RNA extraction. All analyses were performed in three independent experiments.

\section{RNA extraction}

Total RNA was extracted using RNeasy mini columns with on-column DNase treatment following the manufacturer's instructions (Qiagen). The concentration and quality of the RNA were analysed using a NanoDrop 2000 spectrophotometer (Thermo Fisher Scientific, Darmstadt, Germany). The integrity of the RNA was verified using RNA gel electrophoresis.

\section{Human Antibacterial Response $\mathrm{RT}^{2}$ Profiler Array}

The Human Antibacterial Response RT $^{2}$ Profiler PCR Arra/cat. No. 330231 PAHS-148Z (Qiagen, Hilden, Germany) was used to profile the expression of 84 key gens involved in innate immune response to bacteria.

Synthesis of the cDNA was performed with the $\mathrm{RT}^{2}$ first strand kit (Qiagen) according to the manufacturer's instructions at $42{ }^{\circ} \mathrm{C}$ for $15 \mathrm{~min}$ with a 5 -min deactivation step at $95{ }^{\circ} \mathrm{C}$ in an BioRad CFX96 Real-Time System C1000 Thermal Cycler (Biorad, Munic, Germany).

The $\mathrm{RT}^{2}$ SYBR green master mix (Qiagen) $(1350 \mu \mathrm{l}$ per 96-well plate) was mixed with $1248 \mu$ l RNase free water and $102 \mu \mathrm{l}$ cDNA synthesis reaction template, and $25 \mu \mathrm{l}$ PCR components were added to each well of the array. Quantitative real time polymerase chain reaction 
(qRT-PCR) was performed in accordance with the recommendations of the manufacturer. Cycling and detection were done in a Bio Rad CFX96 real time system C1000 thermal cycler (Bio Rad).

\section{qRT-PCR for verification of profiling}

Synthesis of cDNA was performed using the Verso ${ }^{\text {tix }}$ cDNA Kit (Thermo Fisher Scientific) following the manufacturer's instructions. qRT-PCR using the SYBR Green Assay was performed with SensiFast no ROX SYBR Green Mix (Bioline, Luckenwalde, Germany) according to the manufacturer's recommendations. The following primers were used: QuantiTect Primer Assay (Qiagen) Hs_NFKB1_1_SG (NF-kB1), HS_IKBKB_1_SG (IKK $\beta)$, Hs_MAP2K4_1_SG (MAP2K4), Hs_MAPK8_1_SG (MAPK8), Hs_MAPK14_1_ SG (MAPK14), Hs_IRF5_1_SG (IRF5), Hs_JUN_1_SG (Jun), Hs_IRAK3_1_SG (IRAK3), Hs_TOLLIP_1_SG (TOLLIP), and Hs-GAPDH_1_SG (GAPDH) as a housekeeping gene (patents: Roche Molecular Systems). Cycling and detection was performed in a Biorad CX96 cycler (Biorad, Munic, Germany). All samples were tested $3 \times$ in triplicate $(n=9)$.

\section{Data analysis}

The analysis of the profiler arrays was performed using the online analysis tool of the manufacturer based on changes in gene expression for pair-wise comparison with the non-treated control using the $\Delta \Delta \mathrm{Ct}$ method. The results of the qRT-PCR were analyzed using the comparative CT $(\Delta \Delta \mathrm{CT})$ method. The amount of target $\left(2^{-\Delta \Delta C T}\right)$ was obtained by normalizing to an endogenous reference (GAPDH) relative to non-infected control cells. The results are shown as $\log 2$ fold $(\mathrm{x})$ regulation.

\section{Statistical analysis}

The results were analyzed using independent two-sample Student's $t$-test. The character of the evaluation was explorative. Probability of error was set to $5 \%$ and shown as $p$-values.

\section{Results}

\section{SCC- 25 cells treated with $P$. gingivalis W83 isolated} membrane

The analysis of three experiments treating SCC-25 cells with the membrane fraction for $24 \mathrm{~h}$ showed up-regulation of a number of genes that play a role in different biological processes. Up-regulated were genes involved in the TLR signaling cascade, in the NF- $\mathrm{kB}$ pathway and the MAPK pathways. Statistically significant with a $p$-value of $<0.05$ was the up-regulation of $I B K B(4.0 \times)$ and $J U N$ $(8.7 \times)$. The results of this analysis are shown in Table 1 . The Ct values are shown in Additional file 1: Table S4.
Table 1 Up-regulated genes in SCC-25 cells after stimulation with the membrane fraction of $P$. gingivalis W83.

\begin{tabular}{lcl}
\hline Gene Symbol & Fold Regulation & Biological Function \\
\hline IRAK1 & 2.5 & TLR Signaling \\
IRAK3 & 2.2 & \\
IRF5 & 3.1 & \\
TICAM1 & 2.6 & \\
TOLLIP & 2.3 & NLR Signaling \\
TRAF6 & 2.8 & NF-KB Pathway \\
HSP90AA1 & 2.0 & \\
IKBKB* & 4.0 & \\
NFKB1 & 2.6 & MAPK Pathway \\
RELA & 2.5 & \\
JUn* & 8.7 & \\
MAP2K1 & 1.5 & \\
MAP2K4 & 2.9 & \\
MAPK1 & 2.6 & \\
MAPK14 & 2.9 & \\
MAPK8 & 2.4 &
\end{tabular}

Mean values from 3 experiments as $x$-fold regulation compared to the non-infected control. ${ }^{*}=p<0.05$

SCC-25 cells infected with $P$. gingivalis W83 living bacteria Infection of SCC-25 cells with $P$. gingivalis W83 for $24 \mathrm{~h}$ induced up-regulation of genes also with biological functions in TLR signaling, the NF- $\mathrm{BB}$ pathway and MAPK downstream pathway, as well as the cytokine IL-12A. Statistically significant $(p<0.05)$ was the up-regulation of IKBKB $(3.1 \times)$ MAP2K4 $(2.7 \times)$, MAPK14 $(2.7 \times)$ and MAPK8 $(2.6 \times)$. The results of this analysis are shown in Table 2. The Ct values are shown in Additional file 1: Table S4.

\section{PHGK stimulated with $P$. gingivalis W83 membrane}

The analysis of three experiments treating PHGK cells with membrane fraction for $24 \mathrm{~h}$ showed up-regulation of various genes as well. Up-regulated were genes that participate in the TLR signaling, in NLR signaling, apoptosis, inflammatory processes, the NF- $\mathrm{KB}$ pathway and the MAPK downstream signaling. Further up-regulated genes were related to inflammatory response, chemokines, apoptosis and antimicrobial peptides. Also DMBT1, a tumor suppressor gene that participates in various biological processes like mucosal immune response, was up-regulated. The up-regulation of IRF5 was significant $(p<0.05,14.3 \times)$. The results of this analysis are shown in Table 3. The Ct values are shown in (Additional file 2: Table S5).

Quantitative real time polymerase chain reaction (PCR) Quantitative real time PCR (qRT-PCR) of RNA in SCC-25 cells after $24 \mathrm{~h}$ of infection with $P$. gingivalis total 
Table 2 Up-regulated genes in SCC-25 cells after stimulation for $24 \mathrm{~h}$ with living $P$. gingivalis W 83.

\begin{tabular}{|c|c|c|}
\hline Gene Symbol & Fold Regulation & Biological Function \\
\hline IRAK3 & 2.8 & TLR Signaling \\
\hline IRF5 & 2.7 & \\
\hline RAC1 & 3.0 & \\
\hline TICAM1 & 2.5 & \\
\hline TOLLIP & 2.2 & \\
\hline RELA & 2.7 & \\
\hline CASP8 & 2.8 & NLR signaling, Apoptosis \\
\hline IKBKB * & 3.1 & NF-kB Pathway \\
\hline NFKB1 & 3.6 & \\
\hline JUN & 3.2 & MAPK Pathway \\
\hline MAP2K1 & 3.6 & \\
\hline MAP2K4 * & 2.7 & \\
\hline MAPK1 & 3.3 & \\
\hline MAPK14* & 2.7 & \\
\hline MAPK8 * & 2.6 & \\
\hline CCL5 & 2.2 & Chemokines \\
\hline IL12A & 2.4 & Cytokines \\
\hline CASP1 & 4.9 & Apoptosis \\
\hline
\end{tabular}

Mean values from 3 experiments as $x$-fold regulation compared to the non-infected control. ${ }^{*}=p<0.05$

membrane (Fig. 1) showed statistically significant upregulation of the following genes: $I \kappa B \kappa B(4.7 \times), M A P 2 K 4$ $(4.6 \times)$, MAPK14 $(4.2 \times)$ and IRF5 $(9.8 \times)(p<0.01)(n=9)$. Slightly up-regulated were $N F K B 1(4.4 \times), M A P K 8(2.6 \times)$, $\operatorname{JUN}(3 \times)$, IRAK3 $(3.0 \times)$ and TOLLIP $(3.5 \times)(p>0.05)$.

Real-time RNA quantification of SCC-25 cells upon stimulation $P$. gingivalis whole bacteria (Fig. 2) showed statistically significant up-regulation of $I \kappa B \kappa B(2.3 \times)$, IRAK3 $(3.3 \times)(p<0.05)$, IRF5 $(4.1 \times)$, MAPK8 $(3.6 \times)$ and MAPK $14(3.0 \times)(p<0.01)(n=9)$. Only slightly upregulated were $N F \kappa B 1(1.5 \times), M A P 2 K 4(2.5 \times)$, JUN $(1.7 \times)$ and TOLLIP $(2.3 \times)$.

In primary human epithelial cells stimulation with $P$. gingivalis total membrane (Fig. 3) resulted in upregulation of $I \kappa B \kappa B(3.1 \times)$, MAP2K4 $(4.0 \times)$ MAPK 14 $(3.0 \times)(p<0.05), \operatorname{IRF5}(3.0 \times)$ and JUN $(7.7 \times)(p<0.01)$ $(n=9) . N F K B 1(1.4 \times)$, MAPK8 $(1.8 \times)$, IRAK3 $(6.1 \times)$ and TOLLIP $(4.7 \times)$ were also up-regulated as well $(n=$ 9) $(p>0.05)$.

Fig. 4 shows the nuclear- factor kappa B (NF- $\mathrm{KB})$ and mitogen activated protein kinase (MAPK or MKK) signaling pathways induced by activation of toll-like receptors (TLRs) and nucleotide-binding oligomerization domain receptors (NODs). Upregulated genes in oral epithelial cells induced by $P$. gingivalis and its total membrane are indicated by red arrows.
Table 3 Up-regulated genes in primary human gingival keratinocytes $24 \mathrm{~h}$ of infection with membrane fractions of $P$. gingivalis W83.

\begin{tabular}{|c|c|c|}
\hline Gene Symbol & Fold Regulation & Biological Function \\
\hline IRAK3 & 2.5 & TLR Signaling \\
\hline IRF5* & 14.3 & \\
\hline TRAF6 & 2.6 & \\
\hline HSP90AA1 & 2.7 & NLR Signaling \\
\hline NOD1 & 2.3 & \\
\hline NOD2 & 2.0 & \\
\hline XIAP & 2.4 & \\
\hline NAIP & 2.3 & \\
\hline $\mathrm{BIRC3}$ & 2.2 & NLR Sign., Apoptosis \\
\hline IKBKB & 4.0 & NF-kB Pathway \\
\hline NFKB1 & 2.6 & \\
\hline NFKBIA & 2.4 & \\
\hline MAP2K4 & 2.6 & MAPK Signaling \\
\hline MAPK14 & 2.3 & \\
\hline MAPK8 & 2.0 & \\
\hline CRP & 3.8 & Inflammatory Response \\
\hline LBP & 2.6 & \\
\hline LY96 & 2.6 & \\
\hline AKT1 & 2.1 & Inflam. Resp., Apoptosis \\
\hline CCL3 & 3.2 & Chemokines \\
\hline CCL5 & 3.0 & \\
\hline CXCL2 & 2.1 & \\
\hline IL-12A & 2.2 & Cytokines \\
\hline IL-12B & 3.3 & \\
\hline IL18 & 2.7 & \\
\hline CASP1 & 2.1 & Apoptosis \\
\hline PYCARD & 3.5 & \\
\hline RIPK1 & 3.3 & \\
\hline BPI & 3.2 & Antimicrobial Peptides \\
\hline CAMP & 3.3 & \\
\hline MPO & 2.3 & \\
\hline SLPI & 3.6 & \\
\hline DMBT1 & 4.0 & Mucosal Immune Response \\
\hline
\end{tabular}

Mean values from 3 experiments as $x$-fold regulation compared to the non-infected control. ${ }^{*}=p<0.05$

\section{Discussion}

Periodontitis is mainly caused by an oral microbial biofilm, however, progression of the disease is regulated by the immune-inflammatory reaction and the destruction of the teeth supporting tissues [47]. P. gingivalis plays an essential role in the pathogenesis and progression of periodontitis. Among many different mechanisms, it has been shown that $P$. gingivalis differentially activates the NF-кB pathway. After infection with $F$. nucleatum the 


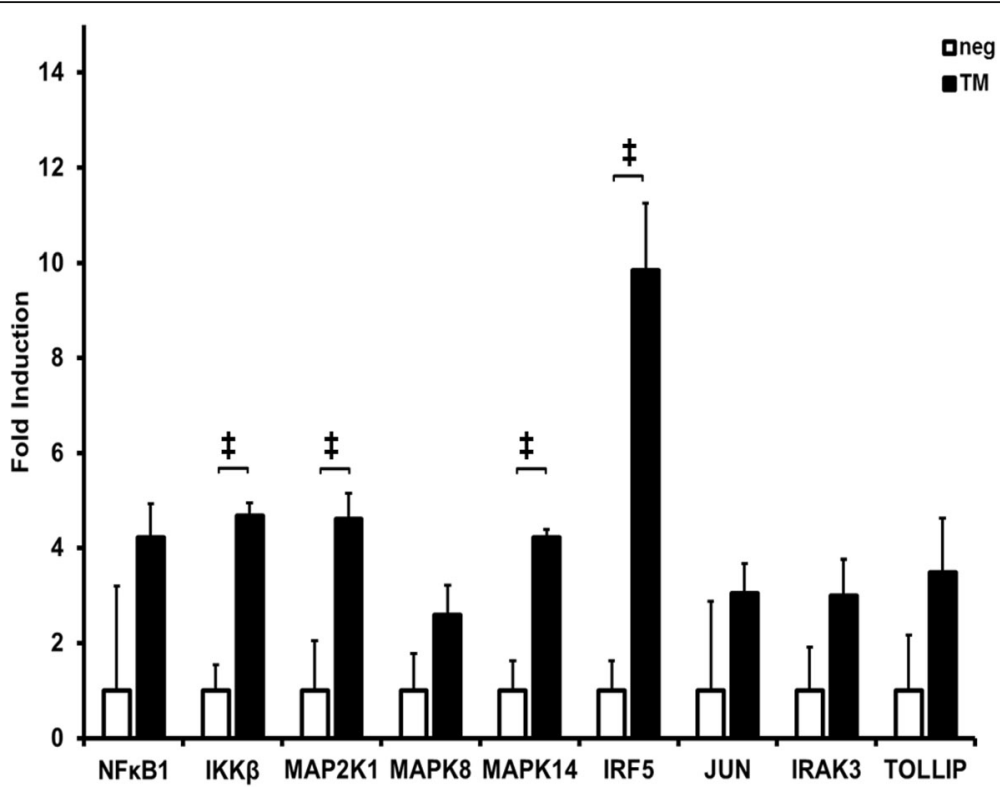

Fig. 1 Up-regulation of genes in P. gingivalis membrane stimulated SCC-25 cells. Up-regulation of NF-KB, IKBKB, MAP2K4, MAPK8, MAPK 14, IRF5, JUN, IRAK3 and TOLLIP in SCC-25 cells after $24 \mathrm{~h}$ stimulation with $P$. gingivalis total membrane fraction (= TM) analyzed by $\Delta \Delta C \mathrm{Ct}$ method, shown as absolute fold induction of RNA expression relative to non-stimulated samples as negative control (= neg), normalized to the house keeping gene GAPDH, $n=9, \neq=p<0.01$

oral epithelial cell line $\mathrm{H} 400$ responded with activation of NFkB. However, a significantly higher number of NF$\mathrm{kB}$ translocations into the nucleus were detected after H400 cell infection with $F$. nucleatum suggesting that these two periodontal pathogens have different molecular influences on these cells [48]. In human monocyte- derived macrophages, $P$. gingivalis gingipains induced secretion of TNF- $\alpha$ and IL-8 and upon stimulation the amount of phosphorylated p38 $\alpha$ MAPK increased [49].

Upon stimulation of primary oral epithelial cells and carcinoma cells with bacterial fractions of $P$. gingivalis, a number of genes were conjointly up-regulated. The

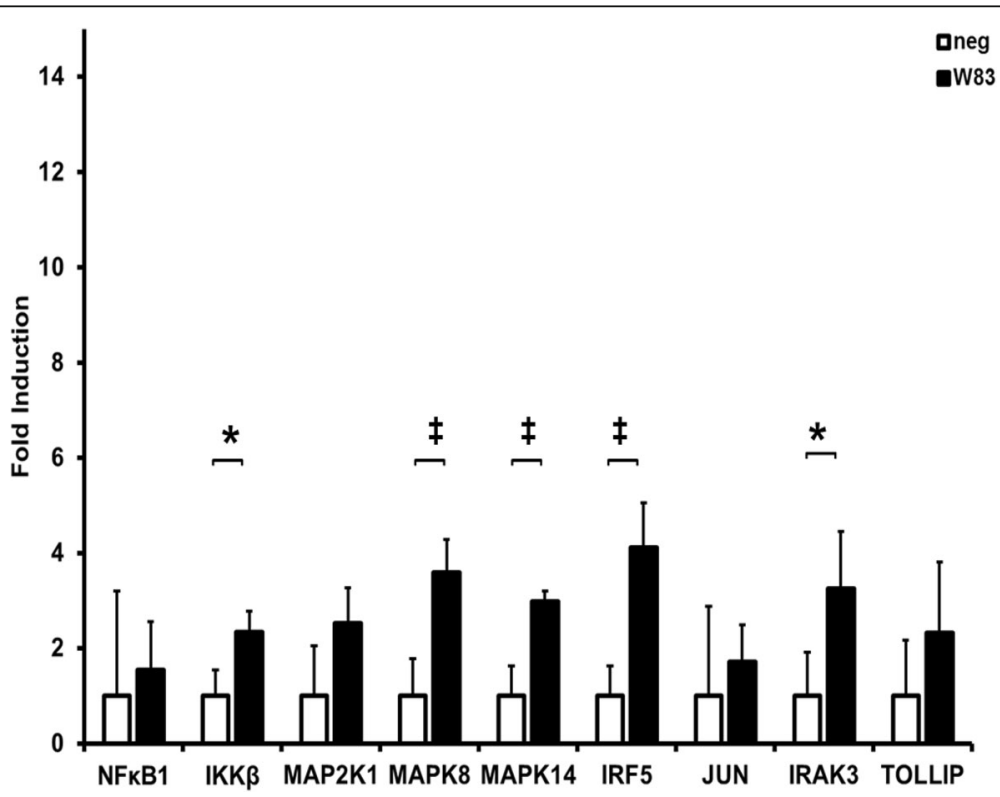

Fig. 2 Up-regulation of genes in P. gingivalis bacteria stimulated SCC-25 cells. Up-regulation of NF-KB, IKBKB, MAP2K4, MAPK8, MAPK 14, IRF5, JUN, IRAK3 and TOLLIP in SCC-25 cells after $24 \mathrm{~h}$ stimulation with $P$. gingivalis W83, whole bacteria (= W83), analyzed by $\Delta \Delta C \mathrm{Ct}$ method, shown as absolute fold induction of RNA expression relative to non-stimulated samples as negative control (= neg), normalized to the house keeping gene GAPDH, $n=9,{ }^{*}=p<0.05, \neq=p<0.01$ 


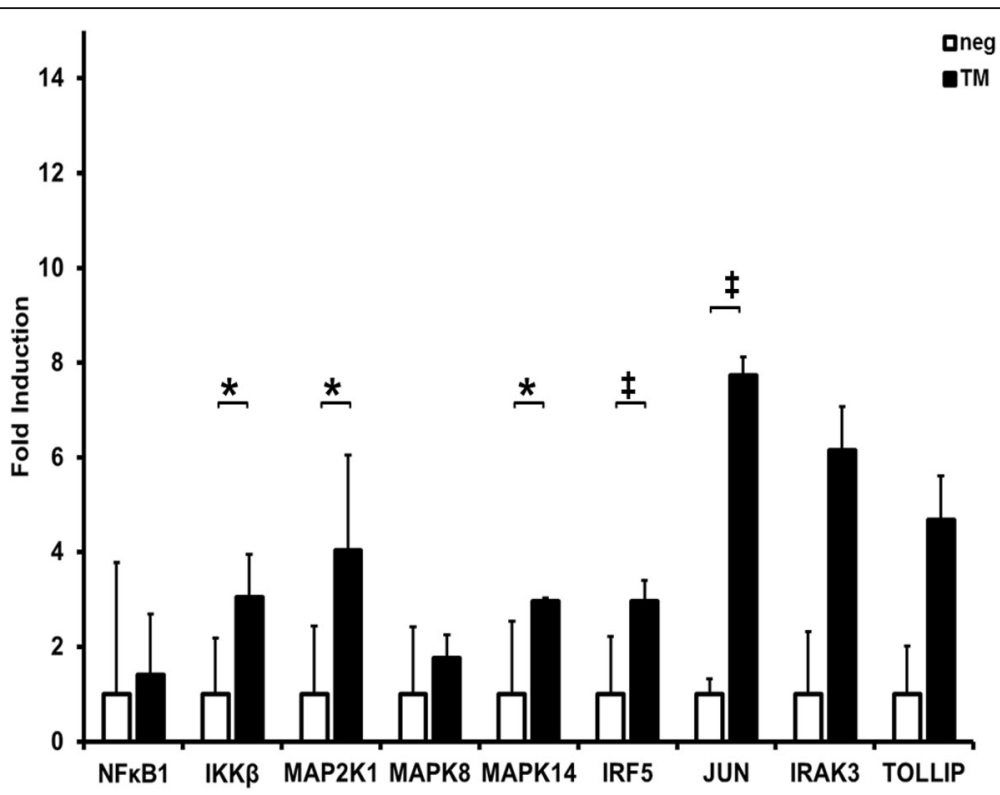

Fig. 3 Up-regulation of genes in P. gingivalis membrane stimulated PHGK. Up-regulation of NF-KB, IKBKB, MAP2K4, MAPK8, MAPK 14, IRF5, JUN, IRAK3 and TOLLIP in PHGK cells after $24 \mathrm{~h}$ stimulation with $P$. gingivalis total membrane fraction $(=\mathrm{TM})$, analyzed by $\Delta \Delta \mathrm{Ct}$ method, shown as absolute fold induction of RNA expression relative to non-stimulated samples as negative control (= neg), normalized to the house keeping gene $\mathrm{GAPDH}, n=9,{ }^{*}=p<0.05, \neq=p<0.01$

genes IKBKB, IRAK3, IRF5, MAP2K4 (MEK4), MAPK14 (p38), MAPK8 (JNK1) and NFKB1 (p50) were upregulated not only in both cell types, but also after infection with whole bacteria of $P$. gingivalis W83 as well as with the membrane fraction. The cytosolic fraction didn't induce altered gene expression (data not shown). NF-KB1 (p50) is a protein subunit of the NF-kB protein complex, a transcription factor central for a number of immunological and inflammatory reactions, including five subunit members - RelA (p65), RelB, c-Rel, p50 (NF-KB1) and p52 with functions as homodimers and heterodimers [50]. The NF-kB transcription factors are dissociated in the cytoplasm by a family of inhibitors of $\kappa B$, the IkBs. The IкB kinase (IKK) complex, including IKBKB, initiates the activation and is activated as well. Further phosphorylation and disintegration of $I_{\kappa} B$ protein results in activation of $\mathrm{NF}-\mathrm{kB}$ [51]. Mitogen-activated protein kinases (MAPKs) are a highly conserved family of Ser/ Thr protein kinases in eukaryotes that are regulating a number of cellular activities such as managing cellular responses to cell stress, and pro-inflammatory cytokines.

Epithelial cells, such as GECs, are able to respond to bacterial challenge by initiation of a deliberated signaling network. The GECs express different receptors on the cell surface or in the cytoplasm. Their activation induces innate immune reactions, including TLRs, nucleotide binding oligomerization domain receptors (NODs) and protease-activated receptors (PARs). It has been shown that surface receptors, such as TLRs and PARs, are activated when corresponding bacterial motifs or proteases are detected. Thus, activation of TLRs and PARs leads to downstream activation of NF- $\mathrm{kB}$ and/or MAPK pathways [52-55]. Activations of TLR and PARs by membrane fractions induce the up-regulation of downstream signaling molecules that were detected in this study. The TLR family shares downstream signaling molecules, amongst them the adaptor molecule myeloid differentiation primary-response protein kinases 88 (MyD88), a shared adaptor protein of TLRs triggers the downstream pathways like NF- $\mathrm{kB}$ and MAPK cascades [56]. Among the MAPK, extracellular signal-regulated kinase 1 and 2 (ERK1/2), cJun N-terminal kinase (JNK) and p38 (also known as MAPK14) kinases have been intensively studied, from which JNK and p38 kinases show a higher responsiveness [57].

In human oral keratinocytes (HOKs) it was demonstrated that $P$. gingivalis LPS could activate both p38 and JNK pathways by inducing phosphorylation of IкBa and p65 transcription factors. These results indicate that induction of LPS binding protein (LBP) expression in HOKs by $P$. gingivalis LPS involves NF- $\mathrm{kB}$ and $\mathrm{p} 38$ MAPK signaling pathways[58]. Further members of the MAPK family are mitogen-activated protein kinase 4 (MEK4 or MAP2K4) and c-Jun NH2 terminal kinase 1 (JNK1 or MAPK8). After stimulation, activated TLR2 may initiate a cascade activation of MAPKs including MEK4 [59]. JNK1 is a downstream target of MEK4 [60]. In a human lung carcinoma type II epithelial cell line (A549) stimulation with LPS enhanced phosphorylation of MEK 4 and JNK1 in a time-dependent manner [61]. 


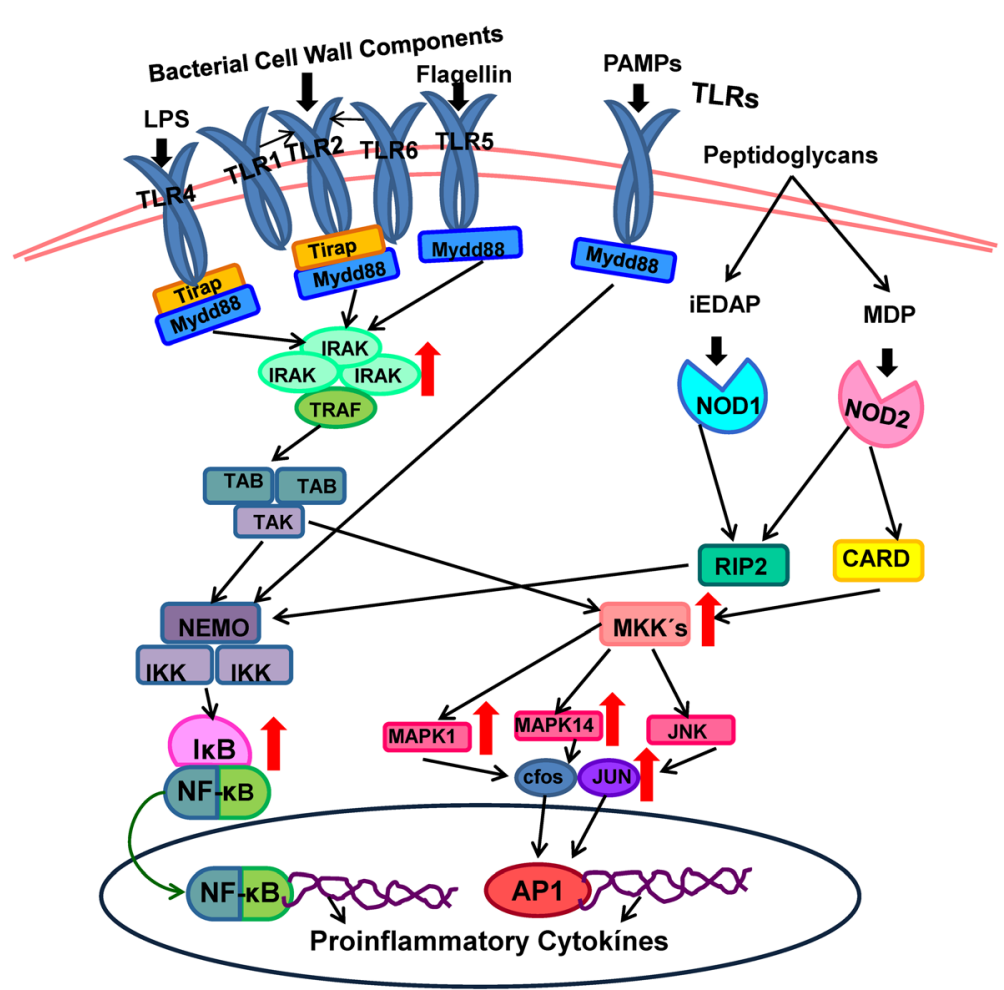

Fig. 4 Pathogen associated pattern recognition receptor activated signaling pathways. Graphics of the nuclear factor-kappa B (NF-kB) and mitogenactivated protein kinase (MAPK or MKK) signaling pathways induced by activation of pathogen associated pattern recognition receptor (PAR) toll like receptors (TLR) and nucleotide-binding oligomerization domain receptors (NOD). TLRs and NODs belong to the key initiators of inflammation in host defence. Diffferent TLRs recognize differencial microbial components. TLR4 detects lipopolysaccharide (LPS), TLR1/2 and TLR2/6 recognize triacylated and diacylated lipoproteins from bacterial wall components and TLR5 is activated by flagellin from the flagella of multiple bacteria. TLRs signal via the adaptor protein MyD88, leading to transforming growth factor- $\beta$-activated kinase 1 (TAK1) activation that induces NF-kB and p38/c-Jun N-terminal kinase (JNK) pathways. Recognition of NOD ligands recruit caspase activation and recruitment domain (CARD) interaction with receptor-

interacting protein kinase RIP2 which leads to activation of RIP2. RIP2 mediates activation IKB kinase. The activation of IKB kinase results in the phosphorylation of inhibitor IKB which releases NF-KB and its nuclear translocation. NF-KB and p38/JNK activated activator protein 1 (AP-1) function as transcription factor for the expression of inflammatory cytokines. The red arrows indicate the upregulated genes in oral epithelial cells induced by $P$. gingivalis and its total membrane that were detected in this study

The results of our study demonstrate that $P$. gingivalis and its membrane fraction, induced RNA up-regulation of the NF-KB and p38 MAPK, MEK4-JNK1 signaling pathways. Furthermore, it was shown that a malignant oral epithelial cell line responded in a similar manner as non-transformed oral keratinocytes. These results are interesting since p38 MAPK and MEK4-JNK1 signaling pathways are known to be involved in tumor microenvironment and cancer growth control.

Head and neck squamous cell carcinoma (HNSCC) tissues express high levels of active p38 and the blockade of its signaling pathway caused significant inhibition of head and neck squamous cell carcinoma (HNSCC) proliferation [62]. Stromal fibroblasts of a variety of invasive malignant tumors express collagenase-1 (matrix metalloproteinase (MMP)-1), which was shown to correlate with the activation of c-Jun NH2-terminal kinase (JNK) and p38 mitogen-activated protein kinase and phosphorylation of c-Jun. It was also demonstrated that JNK2 is required for induction of fibroblast collagenase-3expression [63].

The data of the present study show a possible link between infection with $P$. gingivalis and oral squamous cell carcinomas, considering that periodontal disease has been associated with the risk for oral tumors [64].

Huynh et al. (2016) reported that in human oral epithelial cells interleukin regulation factor (IRF) 6 expression was strongly up-regulated upon challenge with $P$. gingivalis. IRF6 thus is acting downstream of IL-1 receptor (IL-1R)-associated kinase 1 to induce the expression of the IL-1 family cytokine IL-36 gamma responding to $P$. gingivalis [8]. The transcription factor IRF5 is a coregulator of IFN- $\beta$ [65] that exhibits a number of functions, including virus-mediated activation of interferon [66]. The results of the profiler array analysis showed upregulation of IRF5 in SCC- 25 cells by membrane fractions, as well as by whole bacteria (also in PHGK). These results 
were confirmed by quantitative real time PCR assays. These results suggest that IRFs presumably support inflammatory processes upon infection with $P$. gingivalis.

\section{Conclusions}

In malignant and primary human oral epithelial cells, $P$. gingivalis and its membrane fraction induced up-regulation of a number of genes. These genes are involved in the downstream signaling pathway of the pro-inflammatory active transcription factor NF- $\mathrm{kB}$ and some members of the MAPK family. These kinases participate in the downstream signaling pathway for gene induction of pro-inflammatory cytokines and are involved in cancer proliferation and control.

\section{Additional Files}

Additional file 1: Table S4. Ct values of up-regulation of genes in $P$. gingivalis membrane and whole bacteria treated $\mathrm{SCC}-25$ cells. Ct values from qRT-PCR of NF-KB, IKBKB, MAP2K4, MAPK8, MAPK 14, IRF5, JUN, IRAK3 and TOLLIP in SCC-25 cells after $24 \mathrm{~h}$ stimulation with $P$. gingivalis membrane fraction $=T M$ or $P$. gingivalis whole bacteria $=W B$, analyzed by $\Delta \Delta \mathrm{Ct}$ method, shown as absolute fold induction of RNA expression relative to non-stimulated samples, normalized to the house keeping gene GAPDH, $\mathrm{n}=9, \neq=p<0.01$. (DOCX $23 \mathrm{~kb}$ )

Additional file 2: Table S5. Ct values of up-regulation of genes in $P$. gingivalis membrane and whole bacteria treated PHGK cells. Ct values from qRT-PCR of NF-KB, IKBKB, MAP2K4, MAPK8, MAPK 14, IRF5, JUN, IRAK3 and TOLLIP in PHGK cells after $24 \mathrm{~h}$ stimulation with $P$. gingivalis membrane fraction $=\mathrm{TM}$ or $P$. gingivalis whole bacteria $=W B$, analyzed by $\Delta \Delta \mathrm{Ct}$ method, shown as absolute fold induction of RNA expression relative to non-stimulated samples, normalized to the house keeping gene GAPDH, $\mathrm{n}=9, \neq=p<0.01$. (DOCX $19 \mathrm{~kb}$ )

\section{Abbreviations}

IRAK: Interleukin receptor-associated kinase; AG: Antigen; APCs: Antigenpresenting cells; DCs: Dendritic cells; ERK1/2: Extracellular signal-regulated kinase 1 and 2; F. nucleatum: Fusobacterium nucleatum; GECs: Gingival epithelial cells; HNSCC: Head and neck squamous cell carcinoma; HOKs: Human oral keratinocytes; IFN-ү: Interferon gamma; IG: Immunoglobulin; IKBa: Nuclear factor of kappa light polypeptide gene enhancer in B-cells inhibitor alpha; L: Interleukin; LLT-3: Immunoglobulin-like transcript 3; IRF5/6: Interferon regulatory factor 5/6; JNK: c-Jun N-terminal kinase; LBP: LPS binding protein; LPS: Lipopolysaccharide; MAPK: Mitogen-activated protein kinase; MoDCs: Monocyte derived dendritic cells; NF-kB: Nuclear factor-kappaB: NOD: Nucleotide-binding oligomerization domain; P. gingivalis: Porphyromonas gingivalis; PAMPs: Pathogen-associated molecular patterns; PARs: Protease-activated receptors; PD-1: Programmed death-1; PD-L1: Programmed death receptor ligend 1; PHGK: Primary human gingival keratinocytes; PRRs: Pattern recognition receptors; QRT-PCR: Quantitative real time PCR; SCC-25 cells: Squamous cell carcinoma-25 cells; TCR: T-cell receptor; TLR: Toll-like receptor; TOLLIP: Toll-interacting protein; $T_{\text {reg: }}$ : Regulatory T cells; VCAM 1: Vascular cell adhesion protein 1

\section{Acknowledgements}

The authors thank Dr. Uwe Mamat (Research Center Borstel) for the preparation of the bacterial membrane and Manuel Hein and Dörte Grella (Research Center Borstel) for technical assistance.

\section{Funding}

This work was supported by a von-Behring-Röntgen-Stiftung grant. The support consisted of the provision of the financials. There was nether participation in the design of the study, collection, analysis and interpretation of data, nor in writing the manuscript.

\section{Availability of supporting data}

The data set supporting the results of this article is included within the article (and its additional files).

\section{Author's contribution}

SG carried out qPCR studies, participated in the profiling experiments and drafted the manuscript. FJ carried out the profiling experiments. ED participated in the sequence alignment. ED participated in the design of the study and helped to draft the manuscript. JM conceived of the study, and participated in its design and coordination and helped to draft the manuscript. All authors read and approved the final manuscript.

\section{Competing interest}

The authors have no financial or non-financial competing interests to declare. The authors have no conflict of interest to declare.

\section{Consent for publication}

Individual persons data were not applicable.

\section{Ethics approval and consent to participate}

All experiments followed the guidelines of good clinical/laboratory practice (GCP/GLP) and the WHO declaration, Helsinki 1964, latest update Seoul 2008 (59th WMA General Assembly, Seoul, October 2008). The study was approved by the ethical committee of the University of Giessen (Number of the request:22/05; renewal 52/00). All volunteers were informed before the sampling of the tissues and gave their written informed consent.

\section{Author details}

'Department of Periodontology, Justus-Liebig-University of Giessen, Giessen, Germany. ${ }^{2}$ Institute for Medical Microbiology - German Center for Infection Research, DZIF Partner Site Giessen-Marburg-Langen - Justus-Liebig-University of Giessen, Giessen, Germany.

Received: 11 April 2016 Accepted: 16 December 2016 Published online: 05 January 2017

\section{References}

1. Hajishengallis G, Darveau RP, Curtis MA. The keystone-pathogen hypothesis. Nat Rev Microbiol. 2012;10(10):717-25.

2. Darveau RP, Cunningham MD, Bailey T, Seachord C, Ratcliffe K, Bainbridge B, Dietsch M, Page RC, Aruffo A. Ability of bacteria associated with chronic inflammatory disease to stimulate E-selectin expression and promote neutrophil adhesion. Infect Immun. 1995;63(4):1311-7.

3. Deshpande RG, Khan M, Genco CA. Invasion strategies of the oral pathogen porphyromonas gingivalis: implications for cardiovascular disease. Invasion Metastasis. 1998;18(2):57-69.

4. Socransky SS, Haffajee AD. Periodontal microbial ecology. Periodontol 2000. 2005;38:135-87.

5. Dobrovolskaia MA, Medvedev AE, Thomas KE, Cuesta N, Toshchakov V, Ren T, Cody MJ, Michalek SM, Rice NR, Vogel SN. Induction of in vitro reprogramming by Toll-like receptor (TLR)2 and TLR4 agonists in murine macrophages: effects of TLR "homotolerance" versus "heterotolerance" on NF-kappa B signaling pathway components. J Immunol. 2003;170(1):508-19.

6. Ulevitch RJ, Tobias PS. Receptor-dependent mechanisms of cell stimulation by bacterial endotoxin. Annu Rev Immunol. 1995;13:437-57.

7. Hajishengallis G, Sojar H, Genco RJ, DeNardin E. Intracellular signaling and cytokine induction upon interactions of Porphyromonas gingivalis fimbriae with pattern-recognition receptors. Immunol Invest. 2004;33(2):157-72.

8. Huynh J, Scholz GM, Aw J, Kwa MQ, Achuthan A, Hamilton JA, Reynolds EC. IRF6 Regulates the Expression of IL-36 gamma by Human Oral Epithelial Cells in Response to Porphyromonas gingivalis. J Immunol. 2016;196(5):2230-8.

9. Sandros J, Karlsson C, Lappin DF, Madianos PN, Kinane DF, Papapanou PN. Cytokine responses of oral epithelial cells to Porphyromonas gingivalis infection. J Dent Res. 2000;79(10):1808-14.

10. Medzhitov R. Toll-like receptors and innate immunity. Nat Rev Immunol. 2001;1(2):135-45.

11. Medzhitov R, Janeway Jr C. Innate immune recognition: mechanisms and pathways. Immunol Rev. 2000;173:89-97.

12. Kawai T, Akira S. The role of pattern-recognition receptors in innate immunity: update on Toll-like receptors. Nat Immunol. 2010;11(5):373-84. 
13. Ricklin D, Hajishengallis G, Yang K, Lambris JD. Complement: a key system for immune surveillance and homeostasis. Nat Immunol. 2010;11(9):785-97.

14. Bourhis LL, Werts $C$. Role of Nods in bacterial infection. Microbes Infect. 2007;9(5):629-36.

15. Medzhitov R, Janeway Jr C. The Toll receptor family and microbial recognition. Trends Microbiol. 2000;8(10):452-6.

16. Lotze MT, Zeh HJ, Rubartelli A, Sparvero LJ, Amoscato AA, Washburn NR, Devera ME, Liang X, Tor M, Billiar T. The grateful dead: damage-associated molecular pattern molecules and reduction/oxidation regulate immunity. Immunol Rev. 2007;220:60-81.

17. Martinon F, Mayor A, Tschopp J. The inflammasomes: guardians of the body. Annu Rev Immunol. 2009;27:229-65.

18. Martinon F, Gaide O, Petrilli V, Mayor A, Tschopp J. NALP inflammasomes: a central role in innate immunity. Semin Immunopathol. 2007;29(3):213-29

19. Said-Sadier N, Ojcius DM. Alarmins, inflammasomes and immunity. Biomed J. 2012;35(6):437-49.

20. Yilmaz O, Sater AA, Yao L, Koutouzis T, Pettengill M, Ojcius DM. ATPdependent activation of an inflammasome in primary gingival epithelial cells infected by Porphyromonas gingivalis. Cell Microbiol. 2010;12(2):188-98.

21. Johnson L, Atanasova KR, Bui PQ, Lee J, Hung SC, Yilmaz O, Ojcius DM. Porphyromonas gingivalis attenuates ATP-mediated inflammasome activation and HMGB1 release through expression of a nucleosidediphosphate kinase. Microbes Infect. 2015;17(5):369-77.

22. Handfield M, Mans JJ, Zheng G, Lopez MC, Mao S, Progulske-Fox A, Narasimhan G, Baker HV, Lamont RJ. Distinct transcriptional profiles characterize oral epithelium-microbiota interactions. Cell Microbiol. 2005;7(6):811-23.

23. Hasegawa Y, Mans JJ, Mao S, Lopez MC, Baker HV, Handfield M, Lamont RJ. Gingival epithelial cell transcriptional responses to commensal and opportunistic oral microbial species. Infect Immun. 2007;75(5):2540-7.

24. Kinane DF, Galicia JC, Gorr SU, Stathopoulou PG, Benakanakere M. P. gingivalis interactions with epithelial cells. Front Biosci. 2008;13:966-84.

25. Lee JY, Suh JS, Kim JM, Kim JH, Park HJ, Park YJ, Chung CP. Identification of a cell-penetrating peptide domain from human beta-defensin 3 and characterization of its anti-inflammatory activity. Int J Nanomedicine. 2015;10:5423-34.

26. Cohen N, Morisset J, Emilie D. Induction of tolerance by Porphyromonas gingivalis on APCS: a mechanism implicated in periodontal infection. J Dent Res. 2004:83(5):429-33.

27. Groeger S, Domann E, Gonzales JR, Chakraborty T, Meyle J. B7-H1 and B7$D C$ receptors of oral squamous carcinoma cells are upregulated by Porphyromonas gingivalis. Immunobiology. 2011;216(12):1302-10.

28. Dong H, Zhu G, Tamada K, Chen L. B7-H1, a third member of the B7 family, co-stimulates T-cell proliferation and interleukin-10 secretion. Nat Med. 1999:5(12):1365-9.

29. Freeman GJ, Long AJ, Iwai $Y$, Bourque $K$, Chernova T, Nishimura H, Fitz LJ, Malenkovich N, Okazaki T, Byrne MC, et al. Engagement of the PD-1 immunoinhibitory receptor by a novel B7 family member leads to negative regulation of lymphocyte activation. J Exp Med. 2000;192(7):1027-34.

30. Chen Y, Zhang J, Guo G, Ruan Z, Jiang M, Wu S, Guo S, Fei L, Tang Y, Yang C, et al. Induced B7-H1 expression on human renal tubular epithelial cells by the sublytic terminal complement complex C5b-9. Mol Immunol. 2009;46(3):375-83.

31. LaGier AJ, Pober JS. Immune accessory functions of human endothelial cells are modulated by overexpression of B7-H1 (PDL1). Hum Immunol. 2006;67(8):568-78

32. Yamazaki T, Akiba H, Iwai H, Matsuda H, Aoki M, Tanno Y, Shin T, Tsuchiya H, Pardoll DM, Okumura K, et al. Expression of programmed death 1 ligands by murine T cells and APC. J Immunol. 2002;169(10):5538-45.

33. Ishida Y, Agata Y, Shibahara K, Honjo T. Induced expression of PD-1, a novel member of the immunoglobulin gene superfamily, upon programmed cell death. Embo J. 1992;11(11):3887-95.

34. Wang S, Chen L. T lymphocyte co-signaling pathways of the B7-CD28 family. Cell Mol Immunol. 2004;1(1):37-42.

35. Dong H, Strome SE, Salomao DR, Tamura H, Hirano F, Flies DB, Roche PC, Lu J, Zhu G, Tamada K, et al. Tumor-associated B7-H1 promotes T-cell apoptosis: a potential mechanism of immune evasion. Nat Med. 2002;8(8):793-800.

36. Subudhi SK, Zhou P, Yerian LM, Chin RK, Lo JC, Anders RA, Sun Y, Chen L, Wang $Y$, Alegre ML, et al. Local expression of B7-H1 promotes organ-specific autoimmunity and transplant rejection. J Clin Invest. 2004;113(5):694-700.

37. Agata Y, Kawasaki A, Nishimura H, Ishida Y, Tsubata T, Yagita H, Honjo T. Expression of the PD-1 antigen on the surface of stimulated mouse $T$ and $B$ lymphocytes. Int Immunol. 1996;8(5):765-72.
38. Kronenberg M, Rudensky A. Regulation of immunity by self-reactive T cells Nature. 2005;435(7042):598-604.

39. Sakaguchi S, Yamaguchi T, Nomura T, Ono M. Regulatory T cells and immune tolerance. Cell. 2008;133(5):775-87.

40. Tang Q, Bluestone JA. The Foxp3+ regulatory T cell: a jack of all trades, master of regulation. Nat Immunol. 2008;9(3):239-44.

41. Baecher-Allan C, Brown JA, Freeman GJ, Hafler DA. CD4 + CD25high regulatory cells in human peripheral blood. J Immunol. 2001;167(3):1245-53.

42. Kitazawa Y, Fujino M, Wang Q, Kimura H, Azuma M, Kubo M, Abe R, Li XK. Involvement of the programmed death-1/programmed death-1 ligand pathway in CD4 + CD25+ regulatory T-cell activity to suppress alloimmune responses. Transplantation. 2007;83(6):774-82.

43. Francisco LM, Salinas VH, Brown KE, Vanguri VK, Freeman GJ, Kuchroo VK, Sharpe AH. PD-L1 regulates the development, maintenance, and function of induced regulatory T cells. J Exp Med. 2009;206(13):3015-29.

44. Qian Y, Deng J, Geng L, Xie H, Jiang G, Zhou L, Wang Y, Yin S, Feng X, Liu J, et al. TLR4 signaling induces B7-H1 expression through MAPK pathways in bladder cancer cells. Cancer Invest. 2008;26(8):816-21.

45. Allam JP, Peng WM, Appel T, Wenghoefer M, Niederhagen B, Bieber T, Berge S, Novak N. Toll-like receptor 4 ligation enforces tolerogenic properties of oral mucosal Langerhans cells. J Allergy Clin Immunol. 2008;121(2):368-74. e1.

46. Liu J, Hamrouni A, Wolowiec D, Coiteux V, Kuliczkowski K, Hetuin D, Saudemont A, Quesnel B. Plasma cells from multiple myeloma patients express B7-H1 (PD-L1) and increase expression after stimulation with IFN-\{gamma\} and TLR ligands via a MyD88-, TRAF6-, and MEK-dependent pathway. Blood. 2007;110(1):296-304.

47. Van Dyke TE. The management of inflammation in periodontal disease. J Periodontol. 2008;79(8 Suppl):1601-8.

48. Milward MR, Chapple IL, Wright HJ, Millard JL, Matthews JB, Cooper PR. Differential activation of NF-kappaB and gene expression in oral epithelial cells by periodontal pathogens. Clin Exp Immunol. 2007;148(2):307-24.

49. Grenier D, Tanabe S. Porphyromonas gingivalis gingipains trigger a proinflammatory response in human monocyte-derived macrophages through the p38alpha mitogen-activated protein kinase signal transduction pathway. Toxins (Basel). 2010;2(3):341-52.

50. Cario E, Rosenberg IM, Brandwein SL, Beck PL, Reinecker HC, Podolsky DK. Lipopolysaccharide activates distinct signaling pathways in intestinal epithelial cell lines expressing Toll-like receptors. J Immunol. 2000;164(2):966-72.

51. Qin H, Wilson CA, Lee SJ, Zhao X, Benveniste EN. LPS induces CD40 gene expression through the activation of NF-kappaB and STAT-1alpha in macrophages and microglia. Blood. 2005;106(9):3114-22.

52. Darmoul D, Gratio V, Devaud H, Laburthe M. Protease-activated receptor 2 in colon cancer: trypsin-induced MAPK phosphorylation and cell proliferation are mediated by epidermal growth factor receptor transactivation. J Biol Chem. 2004:279(20):20927-34.

53. Fyfe $M$, Bergstrom M, Aspengren S, Peterson A. PAR-2 activation in intestinal epithelial cells potentiates interleukin-1 beta-induced chemokine secretion via MAP kinase signaling pathways. Cytokine. 2005;31(5):358-67.

54. Toubi E, Shoenfeld Y. Toll-like receptors and their role in the development of autoimmune diseases. Autoimmunity. 2004;37(3):183-8.

55. Yu Y, Zeng H, Lyons S, Carlson A, Merlin D, Neish AS, Gewirtz AT. TLR5mediated activation of p38 MAPK regulates epithelial IL-8 expression via posttranscriptional mechanism. Am J Physiol Gastrointest Liver Physiol. 2003;285(2):G282-90

56. Hennessy EJ, Parker AE, O'Neill LA. Targeting Toll-like receptors: emerging therapeutics? Nat Rev Drug Discov. 2010;9(4):293-307.

57. Roux PP, Blenis J. ERK and p38 MAPK-activated protein kinases: a family of protein kinases with diverse biological functions. Microbiol Mol Biol Rev. 2004;68(2):320-44

58. Ding PH, Wang CY, Darveau RP, Jin LJ. Nuclear factor-kappaB and p38 mitogen-activated protein kinase signaling pathways are critically involved in Porphyromonas gingivalis lipopolysaccharide induction of lipopolysaccharide-binding protein expression in human oral keratinocytes. Mol Oral Microbiol. 2013;28(2):129-41.

59. Dillon S, Agrawal A, Van Dyke T, Landreth G, McCauley L, Koh A, Maliszewsk C, Akira S, Pulendran B. A Toll-like receptor 2 ligand stimulates Th2 responses in vivo, via induction of extracellular signal-regulated kinase mitogen-activated protein kinase and c-Fos in dendritic cells. J Immunol. 2004;172(8):4733-43.

60. Flood DG, Finn JP, Walton KM, Dionne CA, Contreras PC, Miller MS, Bhat RV. Immunolocalization of the mitogen-activated protein kinases p42MAPK and 
JNK1, and their regulatory kinases MEK1 and MEK4, in adult rat central nervous system. J Comp Neurol. 1998;398(3):373-92.

61. Chuang CY, Chen TG, Tai YT, Chen TL, Lin YH, Tsai CH, Chen RM. Toll-like receptor 2-mediated sequential activation of MyD88 and MAPKs contributes to lipopolysaccharide-induced sp-a gene expression in human alveolar epithelial cells. Immunobiology. 2011;216(6):707-14.

62. Leelahavanichkul K, Amornphimoltham P, Molinolo AA, Basile JR, Koontongkaew S, Gutkind JS. A role for p38 MAPK in head and neck cancer cell growth and tumor-induced angiogenesis and lymphangiogenesis. Mol Oncol. 2014;8(1):105-18.

63. Westermarck J, Li S, Jaakkola P, Kallunki T, Grenman R, Kahari VM. Activation of fibroblast collagenase-1 expression by tumor cells of squamous cell carcinomas is mediated by p38 mitogen-activated protein kinase and c-Jun NH2-terminal kinase-2. Cancer Res. 2000;60(24):7156-62.

64. Tezal M, Grossi SG, Genco RJ. Is periodontitis associated with oral neoplasms? J Periodontol. 2005;76(3):406-10.

65. Steinhagen F, McFarland AP, Rodriguez LG, Tewary P, Jarret A, Savan R, Klinman DM. IRF-5 and NF-kappaB p50 co-regulate IFN-beta and IL-6 expression in TLR9-stimulated human plasmacytoid dendritic cells. Eur J Immunol. 2013;43(7):1896-906.

66. Barnes BJ, Moore PA, Pitha PM. Virus-specific activation of a novel interferon regulatory factor, IRF-5, results in the induction of distinct interferon alpha genes. J Biol Chem. 2001;276(26):23382-90.

\section{Submit your next manuscript to BioMed Central and we will help you at every step:}

- We accept pre-submission inquiries

- Our selector tool helps you to find the most relevant journal

- We provide round the clock customer support

- Convenient online submission

- Thorough peer review

- Inclusion in PubMed and all major indexing services

- Maximum visibility for your research

Submit your manuscript at www.biomedcentral.com/submit 